\title{
Review of: "Is it easier to use one language variety at a time, or mix them? An investigation of voluntary language switching with bidialectals"
}

Huanhuan Liu

Potential competing interests: The author(s) declared that no potential competing interests exist.

The present study examined the effect of bidialect on voluntary language switching. To investigate mixing costs and switching costs, participants were required to naming single language block and mixed language block. The authors predicted that switching to languages will occur similar costs without matter of a specific language. But voluntary language switching will get benefits in mixed language block. This study will provide empirical evidence in favor of similar control processes underlying bidialectal and bilingual language production.

The study investigates a highly interesting topic for language science and psycholinguistics. It took a novel approach of voluntary language switching to assess the effect of language switching on bidialectals. I have a few concerns with bidialect, participants and theory.

Do dialects and standard languages share the same orthography?

How many participants do this experiment need? Please give a calculation basis.

What does the bidialectal switching provide theoretical significance? 